\title{
ECONOMIC FORCES AND THE STOCK MARKET: AN INTERNATIONAL PERSPECTIVE
}

\author{
James N. Bodurtha, Jr. * \\ D. Chinhyung Cho** \\ Lemma W. Senbet***
}

\section{INTRODUCTION}

At the heart of any asset pricing theory is the view that a few pervasive factors are the dominant source of covariation among asset returns. While the existence of such systematic state variables is implied by comovements of asset prices, the theoretical asset pricing models do not (and perhaps cannot) provide an identity of these exogeneous economic forces. In light of this, empirical studies of factorbased asset pricing models have followed two distinct strategies.

First, they employ factor analysis (Roll and Ross [14]) which implicitly measures unobservable common factors. The focus here is on systematic risk exposures of individual securities or factor loadings. Unfortunately, due to the rotation problem inherent in factor loadings, the nature of pricing factors cannot be identified with this approach. Second, they specify a priori common factors which are measured by macroeconomic or financial data. Chen-Roll-Ross (CRR) [5] posit that five economic and non-equity financial variables-industrial production, unanticipated inflation, changes in anticipated inflation, twist in the yield curve, and changes in the risk premium-are plausible sources of common variation among equity

\footnotetext{
* School of Business, University of Michigan.

** Graduate School of Business, University of Wisconsin-Madison, and Shearson/Lehman/Hutton. *** Graduate School of Business, University of Wisconsin-Madison.
}

The authors wish to thank Cheol S. Eun and K.C. Chan for providing some of the necessary data and Lillyn Teh for computational assistance. Cho is grateful for the summer research support provided by the School of Business, and Bodurtha received research support from Citicorp, NA and a University of Michigan School of Business summer grant. Senbet acknowledges support from the Albright Professorship.

The Global Finance Journal, Volume 1, Number 1, pages 21-46.

Copyright $(1989$ by JAI Press, Inc.

All rights of reproduction in any form reserved.

ISSN: 1044-0283 
returns. Their cross-sectional regression-based empirical study finds that the industrial production and risk premia factors were significant. The evidence for the remaining variables is mixed and it varies with the period of investigation. One problem with this approach is that explanatory variable selection is largely subjective.

This paper extends the work of CRR along two dimensions. The first immediate dimcnsion is an extension into an international setting, showing that both domestic and international forces are relevant determinants of equity returns. The need for considering international factors arises in a fairly integrated international environment that permits investors to diversify their portfolios internationally. Further, international factors would still be important even in a financially segmented environment. In the segmented markets case, domestic stock returns react to international economic news due to international economic interdependence in the real sector.

The second dimension of this paper develops an analytic approach to select macroeconomic factors by reducing the dimensionality of the various relevant economic forces with limited priors. We test both the importance of factors specified a priori and of factors identified by factor analysis through the use of interbattery factor analysis. Time-series data from seven major industrial countries-United States, Japan, United Kingdom, Germany, France, Canada, and Australia are considered. This approach, unlike CRR, neither imposes a linear structure on stock returns and measured economic variables, nor restricts the number of factors or systematic state variablcs a priori. This approach allows the data itself to identify the joint returns structure and number of factors. Factor identification is characterized by the collective feature of a set of economic variables that load relatively heavily on a particular rotated factor. The factor scores corresponding to the rotated loadings are constructed by combining stock returns rather than macroeconomic variables so that factors by themselves can be viewed as pricing factors.

Finally, an asset pricing relationship is tested by the traditional two step procedure of Fama-MacBeth [9], but with the extensions suggested by Shanken $[15,16]$ and Shanken and Weinstein [17]. This approach allows determination of (a) the specified factors' relationship to the cross-section of average equity returns and, (b) the extent the estimated factors are priced individually. Additionally, we test for equivalence of factor prices across countries. Given that we have identified the pricing factors, this restriction should be maintained if the markets are integrated.

The paper is organized as follows. Section II deals with the selection and theoretical justification of the initial set of hypothesized economic factors in international stock returns. Section III introduces our data set and explains the interbattery factor analysis-based methodology. It also outlines all the relevant steps in the empirical analysis and techniques for implementation. Section IV presents our empirical results in three stages. The results in the first two stages pertain to replication of CRR on a country-by-country basis and extension of CRR to include the international analogs of their macroeconomic factors. The third stage pertains to interbattery factor analysis, interpretation, and the analysis of the pricing relationship for a broader set of stock return and macroeconomic data. Section V concludes the paper. 


\section{ECONOMIC DETERMINANTS OF INTERNATIONAL STOCK RETURNS}

A discounted cash flow model can be used to identify economic forces that plausibly impact stock returns. The economic forces may be viewed as state variables that affect stock returns through their influence on expected dividends and the discount rate. Specifically, economic forces such as industrial production are viewed as determining future equity cash flows. Economic forces such as term structure shifts are viewed as determining the discount rate. CRR enumerate five likely candidates as economic state variables: (1) industrial production, (2) term premium (i.e., the premium earned on long-term Government bonds over the Treasury bill rate), (3) junk bond premium (i.e., the return premium paid on low quality corporate bonds over long-term government bond returns), (4) changes in anticipated inflation and (5) unanticipated inflation. Changes in the term premium and junk bond premium are intended to measure twists in the yield curve and changes in the risk premium, respectively. Thus, CRR model equity returns as functions of exogenously determined macroeconomic variables and non-equity asset returns. 1

In identifying the relevant economic forces, CRR limit themselves to the U.S. domestic economy. However, investors diversify their portfolios internationally, and hence international as well as domestic economic forces should generate equity returns. Indeed, the relevance of international macroeconomic variables remains intact even when financial markets are segmented. As long as international forces impact the real sector of the domestic economy, international factors will be relevant.

To bring in international factors, we augment the CRR variable set with five variables that are aggregates of economic forces outside the domestic country. We also identify a broader set of variables that are hypothesized to jointly affect international equity returns. Our interbattery factor analysis identifies combinations of candidate factors from this broader international set of variables by using the joint space of equity returns themselves and the broader set of economic variables. These factors are then used in determining the international pricing relationship.

We can now begin to propose a relevant set of factors. Our starting point is the CRR variables. We add a money supply variable as a relevant economic force either in the purely domestic market or the integrated international market. Though we could have carried out the CRR analysis on a country by country basis, this approach poses an extreme restriction on the structure of the international economy. Such an exercise implicitly assumes segmentation not only of each country"s financial markets, but also of their goods and factors markets. Consequently, we further introduce those variables that characterize international parity relationships in the money and goods markets. Unanticipated deviations in such parity relationships may influence stock market returns.

The two principal variables are deviations from Purchasing Power Parity (PPP) and deviations from Interest Rate Parity (IRP). Deviations from PPP are commonly 
typified as "real" exchange rate changes, and affect a country's current relative competitiveness. Deviations from IRP can be viewed as evidence of different cashflow expectations, international risk premium differences, or international investment restrictions. These factors will also affect a country's Balance of Payments capital account. Therefore, changes in the country's economic competitiveness with the rest of the world are also depicted in the trade, service, and capital accounts of the Balance of Payments. Two additional variables considered in this regard are levels of international reserves and trade accounts, namely exports and imports.

We also include two significant international commodity prices in our hypothesized set of economic factors, namely gold and oil prices. The inclusion of these variables is consistent with the CRR analysis, although they find that oil prices have negligible impact in determining expected stock returns. Of course, that finding may not be the case in the international context. To the extent that oil prices matter, they should show up through changes in industrial production and inflation. However, to the extent that industrial production is an incomplete measure of real economic activity, oil price changes can show up as separate economic influences for particular industries and for those countries which are heavily dependent on oil imports, such as Japan.

We conclude this section by providing a more developed economic rationale for our identification of these variables as potential economic factors. We accept $\mathrm{CRR}^{\prime} \mathrm{s}$ rationale for their variables and the international analogs of these variables. In particular, the variables that remain to be rationalized are the real exchange rate or deviations from PPP, money supply, trade accounts, and international reserves. As a possible economic influence on stock returns, deviations in interest rate parity are also used. The linkage between these deviations and the money or bond market is direct in the sense that interest rate differences affect capital flows across national boundaries. These flows occur largely in the money or bond market, but to the extent that stock markets are viewed as alternative vehicles for international investment, there will also be substitution and wealth effects for equity demands. Also, in the integrated international capital market, changes in interest rate differentials can influence the relevant "international" risk-free rate benchmark in asset pricing; the change in this rate will affect the discount rate applicable to all cash flows, and so affect stock prices.

\section{The Real Exchange Rate or Deviations from PPP}

Since PPP does not generally hold, it is commonly argued that there is a real element in the exchange rate. Thus, changes in the real exchange rate can cause reallocation of resources across industries. The real element in the exchange rate can affect the domestic economy and hence domestic stock returns even under the CRR environment, because stock market prices provide a signal of real activity. The impact that the real exchange rate has on the stock market depends upon trade-flow elasticities. Both the demand-side and supply-side interpretation can 
be invoked to illustrate the role of the real exchange rate as a valid economic force. On the demand side, the immediate impact of a domestic currency depreciation relative to the currencies of a country's major trading partners causes upward pressure on inflation due to increased costs of imports. This, in turn, leads to a reduction in real income and domestic demand. The adverse impact on the real sector will adversely impact the stock market. In the long-run, this effect will dissipate while exchange rates chase PPP. Nonetheless, the demand-side story of currency depreciation is forceful enough to employ the real exchange rate or deviations from PPP as the relevant cconomic determinant of stock returns.

Of course, there is also a supply-side story for the economic importance of deviations from PPP, although it may not be realized immediately. Currency depreciation could improve the position of a typical domestic producer by encouraging exports or through expansion of import substitution. This change has a potentially positive impact on stock prices. That is why the rcal cxchange rate's impact depends upon the relative magnitude of trade elasticities in the import and export sectors of the domestic economy. By the same token, multinational firms whose operations are diversified across currency regions, may be partially hedged against real exchange rate fluctuations. Thus, while there is an economic linkage between real exchange ratc and stock rcturns, determination of the sign of the relationship remains an empirical issue.

\section{Moncy Supply}

There is substantial empirical evidence that links money supply to stock price levels. One theoretical basis for this linkage is the portfolio balance model. Increased nominal money supply leads to a portfolio rebalancing towards other real assets, such as stocks. This asset reallocation results in upward pressure on stock prices. Thus, stock returns respond to unanticipated changes in nominal money supply. On the other hand, purely nominal increases in money supply may lead to greater inflation uncertainty, and the money supply increase could have an adverse consequence on the stock market. Alternatively, real money supply increases manifest themselves in falling real interest rates. Interest rate sensitive sectors are affected postively by falling real interest rates. Not only do firms face lower discount rates against future cash flows, but also respond to rising income by adjusting their investments so as to generate greater sales and profits resulting in higher future cash flows and higher stock prices. Due to the above economic arguments supporting the linkage between stock returns and money supply, the determination of exact sign of the association is an empirical issue. Nonetheless, the underlying economic rationale is sufficient to include money supply as a relevant economic force that can impact stock returns. 


\section{Trade Account and International Reserves}

Changes in the merchandise trade balance are often used to gauge shifts in a country's international competitiveness in the production of traded goods. Of course, one can expand this definition of competitiveness into the current account balance by including service flows (e.g. tourism and investment income). For the U.S., however, the trade account has been the dominant element of the current account. Shifts in competitiveness in the traded goods sector must be balanced by shifts in capital flows or reserve flows. The offsetting flow will depend on the currency exchange regime followed by the trade partners. For instance, the U.S. is now the largest net debtor in the world and its debt is in excess of troubled Third World borrowers, such as Brazil and Mexico. However, the U.S. capital markets are still able to attract foreign capital. Nonetheless, continued buildup of trade deficits has become worrisome to financial markets. In March 1987, a surge in consumer prices was accompanied both by the weakening U.S. dollar and widening trade deficit. Thus, changes in trade accounts can signal changes in cash flows and financial uncertainty which, in turn, impact stock returns. We treat these accounts as relevant economic influences on the stock market.

International reserves are also considered as a potential factor in identifying real exchange rate differences and capital flows. This is because international reserve changes indicate whether or not a trade balance deficit is being financed from abroad, or by a run-down of foreign reserves. In the first case, a healthy domestic investment environment would be indicated if the capital inflows are long-term in nature, and increased foreign investment should increase firm values, all else being equal. This situation would coincide with improved cash-flow forecasts. However, short-term capital inflows would have to be financed by high short-term real rates, and a generally higher yield curve. This situation would imply lower firm values, due to lower potential economic growth or inflation and the higher discount rates. Our consideration of realized deviations from PPP should allow us to differentiate between these two cases when the trade balance deficit is funded by short-term or long-term capital flows. An overvalued currency would tend to be financed by short-term capital flows. Long-term capital inflows would imply good growth prospects and a rising real currency value. While the market mechanisms linking real currency values, trade flows, and investment flows adjust, central banks are likely to be intervening in the markets to counter or slow these adjustments. When central banks are attempting to slow a currency's movement or are unsuccessful in their intervention, their action is known as "leaning against the wind." Under the asset view of exchange rates, central bank intervention against the wind provides an indication that the exchange rate is deviating from its fair value. Based on this phenomenon, it appears that reserve flows may actually predict further exchange rate movements. Of course, central bank reserve flows may also indicate successful intervention which might mitigate some of the shortterm costs of a short-term capital-flow-led real exchange rate change. 


\section{DATA AND METHODOLOGY}

\section{Variable Description and Data Sources}

Our sample is drawn from data on seven major countries-U.S., Canada, France, Germany, U.K., Japan, and Australia. These countries possess relatively well-functioning markets and together constitute the largest segment of international financial markets. If an integrated world market pricing relation does not hold across these countries, then it is unlikely to hold across markets that include developing and/or newly developed economies. Two sets of time series data are utilized: stock returns and macroeconomic variables for the period from January 1973 to December 1983, a period characterized by floating exchange rates. U.S. monthly stock returns are obtained from the monthly return file furnished by the Center for Research in Security Prices (CRSP) at University of Chicago. Data on foreign stocks and the relevent exchange rates are obtained from various issues of Morgan Stanley's Capital International Perspective. This process allows generation of the following stock data:

1. United States (US: 60 stocks)

2. Canada (CA: 28 stocks)

3. United Kingdom (UK: 48 stocks)

4. France (FR: 24 stocks)

5. Germany (GE: 22 stocks)

6. Australia (AU: 26 stocks)

7. Japan (JA: 55 stocks)

The monthly data on macroeconomic variables are obtained from the IMF International Financial Statistics, OECD Main Economic Indicators and the Interactive Data Corporation. The U.S. Treasury variables, junk bond premium and Government bond yields are obtained from Fama's Treasury security database and Ibbotson's Bond database.

Table 1 lists the macroeconomic variables used in the study. The first panel describes the variables that are common to all seven countries. Because the rating of foreign bonds by credit class has only recently begun, the only risk premium variable available is the U.S. junk bond premium. The second panel lists countryspecific variables. The third panel lists the rest-of-the-world indices or international analogs of the CRR macroeconomic variables.

The rest-of-the-world indices are constructed differently depending on the type of study for each country. We construct these indices for a given country by taking weighted averages of the corresponding variables for the other countries. Relative gross national product indices are used for the weights of the rest-of-the-world industrial production (RWIP), and relative market value proportions in 1980, as estimated by Ibbotson, Carr and Robinson [11] for the weights of the rest-of-theworld stock and bond returns. ${ }^{2}$ To be consistent with the CRR study, we use these fixed weights. For the factor analytic approach, as mentioned below, the rest-ofthe-world indices are constructed from the variables listed in the second panel without specifying any prior weights. 
Table 1

DESCRIPTIONS OF MACROECONOMIC VARIABLES

\begin{tabular}{ll} 
Symbols & Descriptions \\
\hline WDGO & Gold Price \\
WDOI & Oil Price \\
USJP & U.S. Junk Bond Premium \\
\hline AI & Anticipated Inflation \\
IR & International Reserve \\
M1 & Money Supply \\
TT & Deviations from the Interest Rate Parity against U.S. \\
TP & Term Premium \\
SP & Stock Price Index \\
WP & Wholesale Price Index \\
IP & Industrial Production Index \\
EX & Export Index \\
IM & Import Index \\
PP & Deviations from Purchasing Power Parity against U.S. \\
\hline RWSC & World Stock Returns \\
RWBC & World Bond Returns \\
RWIP & World Industrial Production Growth Rate
\end{tabular}

Note: 1. Each sample consists of the variables in the first panel, the variables in the second panel with the prefix of US denoting the U.S. macro variables, another set of the variables in the second panel with a prefix of $\mathrm{CA}, \mathrm{UK}, \mathrm{FR}, \mathrm{GE}, \mathrm{AU}$ or JA denoting the other country in the sample and the indices of the variables in the second panel for the remaining five countries are denoted with the prefix of RW. For the United States, TB is used instead of TT. TB represents the Treasury bill rate.

2. The third panel variables are used for the extension of the CRR study. The weights used for the RWIP are based on relative Gross National Production Indices, and the weights for the RWSC and RWBC are relative market value proportions of 1980. See footnote 2 .

3. AI in the second panel is constructed by subtracting the white noise from the original observations of $\mathrm{Ln}\left(\mathrm{WP}_{\mathrm{t}} / \mathrm{WP}_{\mathrm{t}-1}\right)$.

4. The monthly bond return is approximated from the bond yield by using the following formula.

$$
\begin{aligned}
& r_{t}=P_{t}+\frac{1}{12} y_{t-1}-1 \\
& \text { where } P_{t}=\left(\sum_{i=1}^{20} \frac{y_{t-1} / 2}{\left(1+y_{t}\right)^{i / 2}}+\frac{1}{\left(1+y_{t}\right)^{10}}\right)\left(1+y_{t}\right)^{1 / 12}
\end{aligned}
$$

Here, $r_{t}$ and $y_{t}$ are monthly bond return and yearly bond yield, respectively. 


\section{Factor Analytic Methodology}

One of our major departures from CRR is that an a priori structure is not put on the relationship that exists between the stock return variables and macroeconomic variables listed in Table 1 . CRR posit a linear generating process for stock returns with five independent macroeconomic variables. By contrast, we employ interbattery factor analysis to identify the relevant factors from the pool of macroeconomic data. This method allows reduction of the number of explanatory variables in a more objective fashion, while imposing no priors on the number of factors or the nature of the relationship characterizing stock returns and plausible macroeconomic variables. Futhermore, consideration of a large number of theoretically important factors is possible while avoiding the multicollinearity problem present in multifactor pricing tests.

The process can be outlined in five steps:

1. Combine stock returns from a pair of countries with innovations in macroeconomic variables from all seven countries in the sample-country stock return group and macroeconomic innovation group.

2. Use the interbattery factor analysis methodology to estimate the factor loadings for the two groups. As in Cho [6] and Cho, Eun and Senbet [7], the interbattery factor analysis allows estimation of the loadings on a set of common factors between the two groups. This technique has ample advantages over the standard factor analysis (see, for instance, $[6,7,8]$ ).

3. Rotate the factor loadings in order to facilitate the interpretation of factors in terms of the macroeconomic variables. Rotating the estimated factor loadings will not alter the overall fit of the data. Factor interpretation depends on the characteristics of macroeconomic variables that load heavily on a particular factor.

4. Construct factor scores that can be used as surrogates for the macroeconomic factors. Factor scores are estimated as linear combinations of stock returns from the rotated factor loadings of stock returns rather than the macroeconomic variables. By combining stock returns, the factor scores themselves have "prices of risk" in the sense that the factors are portfolios of stock returns. On the other hand, if factors were constructed by combining macroeconomic variables, it is not clear how the estimated factor prices would be interpreted. Construction of factor scores is not straight-forward. AndersonRubin [1] methodology is used in order to maintain orthogonalities among factors. This procedure and its performance relative to other alternatives, $[2$, $4,11,15,16]$, is described in Cho and Pak [8].

5. Use the factors constructed in step 4 to establish a pricing relationship for international equities in the context of international macroeconomic state variables. By using the methodology developed by Shanken $[15,16]$ and implemented by Shanken and Weinstein [17] and Bodurtha [3], linear pricing relationships and the equalities of risk premia between the two countries may be tested. Also, we examine the asymptotic t-statistics on individual factors to determine the exact nature of the pricing factors. 


\section{Implementation}

The economic state variables of interest are innovations in macroeconomic data. These innovations are simply realizations net of expected values of macroeconomic variables, and are estimated by Autoregressive Integrated Moving Average (ARIMA) models. In applying ARIMA, macroeconomic variables with an exponential trend are transformed into growth rates by constructing the logarithmic ratio of the current value to the lagged value so as to satisfy the stationarity assumptions required in the ARIMA analysis. Also, in the process of identifying each series, a parsimonious structure is emphasized over alternative ARIMA specifications. As expected, substantial seasonalities are found in the time series. Most of the specifications follow first-order autoregressive processes with or without a first-order moving average process. A small number of variables are specified as second- or third-order processes. The complete list of $(p, d, q)$ specifications, AR lag- $p$, differencing interval- $d$, and moving average lag- $q$, along with the associated Box-Pierce statistics estimated over 24 periods are presented in Table $2 a$ and Table $2 b$ for the variables of CRR study and the variables of the factor analytic study, respectively.

In the factor analytic approach, carrying out step 1 exactly as specified results in near singular correlation matrices and causes difficulty in carrying out step 2 . In order to overcome this problem, the dimension of macroeconomic variables is reduced through factor analysis on each macroeconomic innovation which varies across the rest of the countries outside of the particular pair of countries being tested. As an example, for the U.S./U.K. pair, an index of the innovations in unanticipated inflation was generated (i.e, the innovation in WP in Table $2 b$ ) for the remaining five countries, $\mathrm{CA}, \mathrm{FR}, \mathrm{GE}, \mathrm{AU}$, and JA, by performing factor analysis on the five WP innovation times series and estimating a factor score. Based on the estimation results, it is possible for a macroeconomic variable to show up in more than one index. However, the resulting maximum number is 2 . In Table 3 , that number is depicted for the pairs across the U.S. with each of the other six countries. For instance, column 1 and row 3 relate to the U.S./CA pair. In this case, a one factor index of innovations in money supply for the rest of five countries outside U.S. and Canada was sufficient, defined RWM11.

Next, we generate a sample by first picking a pair of countries (e.g. U.S./CA) for the stock return group. To complete the sample, we then form a macroeconomic data group consisting of (a) variables in the first panel of Table 1, (b) variables in the second panel of Table 1 for the paired countries with the prefixes of U.S. and $\mathrm{CA}$, and $(\mathrm{c})$ the indices of the variables reported in Table 3 for the remaining five countries. These rest-of-world index variables will be identified with the prefix of RW; RWM1 indicates the innovation in money growth in the rest-of-world, not U.S. and CA. Similarly, other samples are generated by picking another pair and repeating the three-step data series construction process. Note that the number of indices may vary across different country-pair samples. Hence, the number of macroeconomic variables do also. The total number of macroeconomic innovations for each of the six samples are $37,39,37,36,34$, and 37 for the pairs with CA, UK, FR, GE, AU, and JA, respectively. For the interbattery factor analysis, we use the 0.05 significance level to estimate the number of common factors. 
Table 2a

ARIMA SPECIFICATIONS OF VARIABLES FOR CRR STUDY

\begin{tabular}{|c|c|c|c|c|}
\hline & US $(p, d, q)$ & B-P & $C A(p, d, q)$ & B-P \\
\hline TP & $(0,0,1)$ & 33.0 & $(1,0,1)$ & 38.5 \\
\hline $\mathrm{JP}$ & $(1,0,1)$ & 23.1 & $(1,0,0)$ & 25.6 \\
\hline WP & $(1,1,1)(0,0,1) 12 \ln$ & 33.8 & $(1,1,1)(0,0,1) 12 \mathrm{ln}$ & 32.8 \\
\hline IP & $(1,1,0)(0,1,1) 12 \ln$ & 21.0 & $(0,1,1)(0,1,1) 12 \mathrm{ln}$ & 6.9 \\
\hline SP & $(0,1,1) \ln$ & 23.9 & $(0,1,0) \ln$ & w.n. \\
\hline OI & $(0,1,1) \mathrm{ln}$ & w.n. & $(0,1,0) \ln$ & w.n. \\
\hline RWSC & $(0,0,1\}$ & 29.7 & $(0,0,1)$ & 21.2 \\
\hline RWBC & $(0,0,1)$ & 15.7 & $(0,0,1)$ & 18.3 \\
\hline \multirow[t]{2}{*}{ RWIP } & $(0,0,0)(0,1,1) 12$ & 21.2 & $(1,0,0),(0,1,1) 12$ & 26.8 \\
\hline & $\mathrm{UK}(\mathrm{p}, \mathrm{d}, \mathrm{q})$ & B-P & $F R(p, d, q)$ & $\mathrm{B}-\mathrm{P}$ \\
\hline $\mathrm{TP}$ & $(0,0,1)$ & 17.3 & $(0,1,1\}$ & 35.5 \\
\hline $\mathrm{JP}$ & $(1,0,1)$ & 42.8 & $(1,0,0)$ & 16.7 \\
\hline WP & $(1,1,1)(0,1,1) 12 \ln$ & 26.5 & $(1,1,1)(0,1,1) 12 \ln$ & 23.8 \\
\hline IP & $(0,1,1)(0,1,1) 12 \mathrm{ln}$ & 22.8 & $(2,1,0)(0,1,1) 12 \mathrm{ln}$ & 32.1 \\
\hline SP & $(0,1,1) \ln$ & 21.0 & $(0,1,1) \ln$ & 30.5 \\
\hline & $(0,1,0) \ln$ & w.n. & $(0,1,0) \ln$ & w.n. \\
\hline RWSC & $(1,0,0)$ & 31.8 & $(1,0,0)$ & 14.8 \\
\hline RWBC & $(1,0,0)$ & 23.0 & $(0,1,1\}$ & 28.7 \\
\hline \multirow[t]{2}{*}{ RWIP } & $(1,0,0)(0,1,1) 12$ & 22.8 & $(1,0,0)(0,1,1) 12$ & 21.3 \\
\hline & $\mathrm{GE}(\mathrm{p}, \mathrm{d}, \mathrm{q})$ & B-P & $\mathrm{AU}(\mathrm{p}, \mathrm{d}, \mathrm{q})$ & B-P \\
\hline TP & $(1,0,0)$ & 18.6 & $(3,0,0)$ & 21.5 \\
\hline $\mathrm{JP}$ & $(0,0,0)$ & w.n. & $(1,0,0)$ & 22.9 \\
\hline WP & $(3,1,0)(0,1,1) 12 \ln$ & 32.0 & $(1,1,1)(0,1,1) 12 \ln$ & 21.4 \\
\hline IP & $(0,1,1)(1,1,1) 12 \ln$ & 32.0 & $(0,1,1)(0,1,1) 12 \mathrm{ln}$ & 27.2 \\
\hline SP & $(0,1,1) \ln$ & 35.6 & $(0,1,1) \ln$ & 15.0 \\
\hline OI & $(0,1,0) \ln$ & w.n. & $(0,1,0) \mathrm{ln}$ & w.n. \\
\hline RWSC & $(0,0,1)$ & 19.2 & $(0,0,1)$ & 23.9 \\
\hline RWBC & $(1,0,1)$ & 28.5 & $(1,0,0)$ & 17.4 \\
\hline \multirow[t]{2}{*}{ RWIP } & $(1,0,0)(0,1,1) 12$ & 28.1 & $(0,0,0)(0,1,1) 12$ & 15.4 \\
\hline & $J A(p, d, q)$ & B-P & & \\
\hline $\mathrm{TP}$ & $(1,0,0)$ & 37.1 & & \\
\hline $\mathrm{JP}$ & $(0,0,0)$ & w.n. & & \\
\hline WP & $(1,1,0)$ & 17.3 & & \\
\hline IP & $(3,1,0)(0,1,1) 12 \ln$ & 44.6 & & \\
\hline SP & $(0,1,1) \ln$ & 27.5 & & \\
\hline OI & $(0,1,0) \ln$ & w.n. & & \\
\hline RWSC & $(0,0,1)$ & 24.6 & & \\
\hline RWBC & $(1,0,0)$ & 29.1 & & \\
\hline RWIP & $(1,0,0)(0,1,1) 12$ & 44.7 & & \\
\hline
\end{tabular}

Note: 1. B-P represents the Box-Pierce statistic for 24 lags.

2. w.n. and ln mean white noise and logarithmic transformation, respectively. 
Table $2 b$

ARIMA SPECIFICATIONS OF VARIABLES FOR FACTOR ANALYTIC STUDY

\begin{tabular}{|c|c|c|c|c|}
\hline & $\mathrm{US}(\mathrm{p}, \mathrm{d}, \mathrm{q})$ & B-P & $C A(p, d, q)$ & $\mathrm{B}-\mathrm{P}$ \\
\hline$\overline{I R}$ & $(1,1,1) \ln$ & 24.9 & $(2,1,1) \ln$ & 27.7 \\
\hline M1 & $(1,1,0)(0,1,1) 12 \ln$ & 24.6 & $(2,1,2)(0,1,1) 12 \ln$ & 27.4 \\
\hline $\mathrm{TT}$ & $(2,1,0)$ & 32.1 & $(2,0,0)(0,0,1) 12$ & 18.2 \\
\hline $\mathrm{TP}$ & $(0,0,1)$ & 33.0 & $(0,0,0)$ & w.n. \\
\hline SP & $(0,1,1) \ln$ & 23.9 & $(0,1,0) \ln$ & w.n. \\
\hline WP & $(2,2,2)(0,0,1) 12 \ln$ & 24.5 & $(1,1,2)(0,0,1) 12 \ln$ & 29.4 \\
\hline IP & $(1,1,0)(0,1,1) 12 \ln$ & 21.0 & $(0,1,1)(0,1,1) 12 \ln$ & 7.4 \\
\hline EX & $(0,1,1)(0,1,0) 12 \ln$ & 19.4 & $(0,1,2)(0,1,1) 12 \ln$ & 35.5 \\
\hline IM & $(0,1,2)(0,1,1) 12 \ln$ & 24.1 & $(0,1,2)(0,1,1) 12 \ln$ & 36.5 \\
\hline \multirow[t]{2}{*}{ PP } & n.a. & & $(1,0,1)$ & 28.0 \\
\hline & UK $(p, d, q)$ & B-P & $F R(p, d, q)$ & B-P \\
\hline IR & $(1,1,1) \ln$ & 22.0 & $(1,1,1) \ln$ & 19.9 \\
\hline M1 & $(0,1,0) \ln$ & w.n. & $(0,1,0)(0,1,1) 12 \ln$ & 13.9 \\
\hline $\mathrm{TT}$ & $(0,0,0)$ & w.n. & $\{0,0,0\}$ & w.n. \\
\hline GT & $(0,0,1)$ & 19.3 & $(0,0,0)$ & w.n. \\
\hline SP & $(0,1,1)$ & 15.9 & $(0,1,1) \ln$ & 29.8 \\
\hline WP & $(0,1,0) \ln$ & w.n. & $(0,1,0)$ ln & w.n. \\
\hline IP & $(1,1,0)(0,1,1) 12 \ln$ & 28.4 & $(1,1,0)(0,1,1) 12 \ln$ & 13.5 \\
\hline $\mathrm{EX}$ & $(0,1,2)(0,0,1) 12 \ln$ & 25.7 & $(0,1,2)(0,1,1) 12 \ln$ & 27.6 \\
\hline IM & $(0,1,1)(0,0,1) 12 \ln$ & 25.5 & $\{3,1,0\}(0,1,1) 12 \ln$ & 31.7 \\
\hline \multirow[t]{2}{*}{ PP } & $(0,0,0)$ & w.n. & $(0,0,0)$ & w.n. \\
\hline & $G E(p, d, q)$ & B-P & $\mathrm{AU}(\mathrm{p}, \mathrm{d}, \mathrm{q})$ & $\mathrm{B}-\mathrm{P}$ \\
\hline IR & $(0,1,1) \ln$ & 22.6 & $(1,1,0) \ln$ & 31.5 \\
\hline M1 & $(0,1,0)(0,0,1) 12 \ln$ & 27.7 & $(1,1,0\}(0,1,1) 12 \ln$ & 28.8 \\
\hline $\mathrm{TT}$ & $(0,0,0)$ & w.n. & $(0,0,0)$ & w.n. \\
\hline GT & $\mid 0,0,1\}$ & 27.7 & $(0,0,0\}(0,0,1) 12$ & 13.3 \\
\hline SP & $(1,1,0) \ln$ & 36.3 & $(0,1,1) \ln$ & 19.3 \\
\hline WP & $(0,1,0) \ln$ & w.n. & $(0,1,0) \ln$ & w.n. \\
\hline IP & $(1,1,0)(0,1,1) 12 \ln$ & 21.0 & $(1,1,0)(0,1,1) 12 \ln$ & 28.4 \\
\hline $\mathrm{EX}$ & $(2,1,0)(0,1,1) 12 \ln$ & 41.4 & $(0,1,1)(0,0,1) 12 \ln$ & 18.3 \\
\hline IM & $(2,1,0)(0,1,1) 12 \ln$ & 21.3 & $(0,1,1)(0,1,1) 12 \ln$ & 29.2 \\
\hline \multirow[t]{2}{*}{ PP } & $(0,0,0)(0,0,1) 6$ & 13.1 & $(0,0,0)$ & w.n. \\
\hline & $\mathrm{JA}(\mathrm{p}, \mathrm{d}, \mathrm{q})$ & B-P & WD $(p, d, q)$ & B-P \\
\hline$\overline{\mathrm{IR}}$ & $(1,1,1) \ln$ & 12.5 & OI $\quad(0,1,1) \ln$ & 15.6 \\
\hline M1 & $(0,1,0)(0,1,1) 12 \ln$ & 27.2 & GO $\quad(0,1,1) \mathrm{ln}$ & 34.2 \\
\hline TT & $(0,0,0)$ & w.n. & & \\
\hline GT & $(0,0,1)(0,0,1) 12$ & 33.3 & & \\
\hline SP & $(0,1,1)$ In & 20.4 & & \\
\hline WP & $(0,1,0) \ln$ & W.II. & & \\
\hline IP & $(0,1,0 \mid(0,1,1) 12 \ln$ & 26.5 & & \\
\hline EX & $(0,1,3)(0,1,1) 12 \ln$ & 20.9 & & \\
\hline IM & $(0,1,1)(0,1,1) 12 \mathrm{ln}$ & 29.5 & & \\
\hline PP & $(0,0,0)$ & w.n. & & \\
\hline
\end{tabular}

Note: 1. B-P represents the Box-Pierce statistic for 24 lags.

2. w.n. and $\ln$ mean white noise and logarithmic transformtion, respectively.

3. For US, PP is not available and TB is used instead of TT. 
Table 3

NUMBER OF FACTORS USED FOR THE CONSTRUCTION OF THE REST-OF-THE-WORLD INDICES IN THE FACTOR ANALYTIC STUDY

\begin{tabular}{|c|c|c|c|c|c|c|c|c|c|c|c|c|}
\hline & & $\mathrm{CA}$ & & UK & & FR & & $\mathrm{GE}$ & & $\mathrm{AU}$ & & JA \\
\hline & No. & $p$ & No. & $\mathrm{p}$ & No. & $\mathrm{p}$ & No. & $p$ & No. & $\mathrm{p}$ & No. & $\mathrm{p}$ \\
\hline $\mathrm{AI}$ & 1 & 0.969 & 1 & 0.990 & 1 & 0.966 & 1 & 0.999 & 1 & 0.930 & 1 & 0.927 \\
\hline IR & 1 & 0.077 & 1 & 0.196 & 1 & 0.217 & 1 & 0.659 & 1 & 0.293 & 1 & 0.461 \\
\hline M1 & 1 & 0.241 & 2 & 0.238 & 1 & 0.089 & 2 & 0.345 & 1 & 0.487 & 1 & 0.072 \\
\hline TT & 2 & 0.875 & 2 & 0.204 & 2 & 0.209 & 2 & 0.251 & 1 & 0.291 & 2 & 0.403 \\
\hline $\mathrm{TP}$ & 2 & 0.382 & 2 & 0.537 & 1 & 0.379 & 1 & 0.401 & 2 & 0.848 & 2 & 0.414 \\
\hline SP & 1 & 0.446 & 2 & 0.371 & 2 & 0.414 & 1 & 0.052 & $\overline{1}$ & 0.061 & $\overline{1}$ & 0.054 \\
\hline WP & 2 & 0.758 & 2 & 0.550 & 2 & 0.153 & 2 & 0.115 & 1 & 0.244 & 2 & 0.310 \\
\hline IP & 1 & 0.963 & 1 & 0.870 & 1 & 0.876 & 1 & 0.940 & 1 & 0.788 & 1 & 0.838 \\
\hline EX & 1 & 0.627 & 1 & 0.892 & 1 & 0.547 & 1 & 0.453 & 1 & 0.550 & 1 & 0.274 \\
\hline IM & 1 & 0.206 & 1 & 0.159 & 1 & 0.835 & 1 & 0.991 & 1 & 0.120 & 1 & 0.775 \\
\hline PP & 2 & 0.818 & 2 & 0.410 & 2 & 0.102 & 1 & 0.059 & 1 & 0.131 & 2 & 0.358 \\
\hline Total & 15 & & 17 & & 15 & & 14 & & 12 & & 15 & \\
\hline
\end{tabular}

Note: 1. No. and $p$ mean the number of factors and p-levels, respectively.

2. Five percent significance level is used to determine the number of factors.

3. All countries are paired with the U.S., and the remaining five countries' common loading(s) on the economic factor is extracted.

Step 3 is implemented by using the Varimax factor rotation which maximizes the variance of the squared factor loadings for each column of the rotated loading matrix. Since factor loadings are partial correlation coefficients between the variables and the factors, the loadings themselves are used in assigning macroeconomic variables to a particular factor. By examining the nature of the macroeconomic variables that are highly correlated with a particular factor, a meaningful economic interpretation can be given to the factor. For this purpose, loadings that are at least equal to 0.3 will be used, although the loadings that are 0.25 or higher will also be reported. Further details on this procedure can be obtained from Harman [10] and Kim and Mueller [12]. Step 4 is rather straightforward and needs no further explanation, except to note the importance of the orthogonal factor scores to eliminate the multicollinearity problems.

In implementing step 5, cross-sectional factor test tradition could have been followed by testing the pricing relationship on the initial factor loadings (e.g., [14]) without knowledge of the relevant factors. However, this traditional procedure precludes testing factor price significance individually. We overcome this limitation by using the previously constructed factor scores in step 4 as prespecified factors and examine the pricing relationship between these factors and international stock returns. For this purpose, the cross-sectional $\mathrm{T}^{2}$ test (CSRT) developed by Shanken 
$[15,16]$ is used. The major advantage of the CSRT statistic is that its small sample distribution can be approximated by a well-known distribution, and the statistic is adjusted for the errors-in-variables (EIV) problem. The adjustment for the errorin-variables problem can be viewed as an alternative to the CRR's use of the traditional portfolio grouping approach. However, the latter procedure only reduces the EIV. Further details on the CSRT approach, in the context of our international pricing relationship tests, are given in Bodurtha [3].

\section{EMPRICAL RESULTS}

Our empirical results pertain to three distinct analyses. The first experiment attempts to replicate the CRR analysis through the use of the country by country experimental basis and different data. The second stage performs CRR-type analysis on an expanded macroeconomic data set that includes the five CRR variables plus the domestic country stock return index, the rest-of-the-world industrial production growth, the rest-of-the-world stock return index, the restof-the-world bond return index, and the oil price. The third stage of this empirical analysis pertains to interbattery factor analysis, factor interpretation, and crosssectional pricing relationship tests involving a combined set of macroeconomic innovations and stock returns from seven major industrial countries.

\section{Replicating Chen-Roll-Ross}

The results of replicating CRR on three countries-U.S., U.K., and Japanwith the five CRR macroeconomic variables are reported in Table 4a. Generalized least squares are used for estimation. Unlike CRR who use the traditional portfolio grouping approach to deal with EIV, we use Shanken's [15] approach.

The EIV adjustment tends to reduce the t-values, and, indeed, all the coefficients turn out to be insignificant with EIV adjustment for the U.S. case. Without the EIV adjustment, industrial production shows up as a significant variable. In the U.K. case, even less satisfying results are evident. All of the coefficient estimates associated with macroeconomic variables turn out to be insignificant with or without EIV adjustment. The Japanese case is not unlike U.S. and U.K. cases with the EIV adjustment; the estimated macroeconomic variable coefficients are insignificant. However, industrial production and unanticipated inflation turn out to be significant without the EIV adjustment. Overall, the data tend to perform better for Japan than the U.S. and U.K. The U.K. performs the worst.

Thus, our empirical results are not as promising as CRR's results, who found that industrial production and changes in the junk bond premium were significant variables in explaining expected stock returns. It should be recalled, though, that the CRR analysis tends to generate a better fit for longer periods, such as 1958-84, and for shorter periods the results tended to be unsatisfactory. Not only do we use a different sample period, but also we analyze the data over a shorter time period. Consequently, our analysis is more comparable to CRR's subperiod 
Table 4a

PRICING RESULTS OF THE CRR REPLICATION (5 factors)

\begin{tabular}{llllllll} 
& & Const. & AI & TP & JP & WP & IP \\
\hline \multirow{2}{*}{ US } & Coef. & 0.982 & -0.000 & -0.167 & -0.002 & 0.000 & 0.002 \\
& EIV & 3.730 & -0.215 & -0.639 & -0.005 & 0.066 & 1.582 \\
0.980 & W.O.EIV & 3.810 & -0.292 & -0.947 & -0.008 & 0.102 & 2.263 \\
& & & & & & & \\
UK & Coef. & 0.817 & 0.001 & 0.060 & -0.317 & 0.001 & -0.004 \\
& EIV & 1.916 & 0.593 & 0.178 & -0.493 & 0.634 & -0.919 \\
0.999 & W.O.EIV & 1.961 & 0.686 & 0.261 & -0.647 & 0.805 & -1.129 \\
& & & & & & & \\
JA & Coef. & 0.558 & 0.000 & -0.191 & -0.305 & 0.002 & 0.004 \\
& EIV & 2.801 & 0.018 & -0.705 & -0.524 & 1.715 & 1.612 \\
0.550 & W.O.EIV & 2.996 & 0.023 & -0.982 & -0.754 & 2.247 & 2.201 \\
& & & & & & & \\
CRR & Coef. & 0.005 & -0.001 & 0.421 & 0.241 & -0.001 & -0.005 \\
& EIV & 0.929 & -0.694 & 1.076 & 0.379 & -0.352 & -1.463 \\
0.746 & W.O.EIV & 1.082 & -0.849 & 1.435 & 0.481 & -0.483 & -1.772 \\
& & & & & & & \\
\hline
\end{tabular}

Note: 1. Const., Coef., EIV, and W.O.EIV mean respectively constant, coefficient, t-statistics with errors-in-variables adjustment, and t-statistics without errorsin-variables adjustment.

2. CRR in the bottom panel shows the results of U.S. stock portfolios that are actually used by CRR.

3. Numbers below country names are p-levels of the F-statistics corresponding to the linearity tests.

analysis. These results are not markedly different from ours in terms of generating significant macroeconomic variable coefficients. ${ }^{3}$

\section{Internationalizing Chen-Roll-Ross}

Table $4 \mathrm{~b}$ reports the results of tests of the cross-sectional pricing relationship, fitting average domestic stock returns with domestic country and international aggregate economic variables. As one might suspect, a better fit is obtained by including the international variables in the regressions. With the EIV adjustment, only the rest-of-the-world industrial production coefficient estimate turns out to be significant. (The negative coefficient is economically plausible, given that the aggregate industrial production variable involved only the rest-of-the-world). Without the EIV adjustment, three economic variables, domestic industrial production growth, the rest-of-the-world industrial production growth, and the rest-of-the-world bond returns, are significant. This finding is certainly a marked improvement over the domestic country-based results. Even for the U.K., the restof-the-world industrial production factor price estimate turns out to be significant. 
Table $4 b$

PRICING RESULTS OF THE CRR EXTENSION (10 Factors)

\begin{tabular}{|c|c|c|c|c|c|c|c|}
\hline & & Const. & $\mathrm{AI}$ & $\mathrm{TP}$ & $\mathrm{JP}$ & WP & IP \\
\hline \multirow[t]{2}{*}{ US } & Coef. & 0.910 & 0.000 & -0.009 & -0.161 & -0.000 & 0.002 \\
\hline & EIV & 2.922 & 0.287 & -0.030 & -0.411 & -0.080 & 1.505 \\
\hline \multirow[t]{6}{*}{0.992} & W.O.EIV & 3.157 & 0.391 & -0.043 & -0.575 & -0.124 & 2.135 \\
\hline & & $\mathrm{SP}$ & OI & RWSC & RWBC & RWIP & \\
\hline & Coef. & -0.003 & 0.009 & -0.280 & -0.432 & -0.064 & \\
\hline & EIV & -0.601 & 0.897 & -1.177 & -1.649 & -1.974 & \\
\hline & W.O.EIV & -0.990 & 1.445 & -1.632 & -2.243 & -2.628 & \\
\hline & & Const. & $\mathrm{AI}$ & $\mathrm{TP}$ & $\mathrm{JP}$ & WP & IP \\
\hline \multirow[t]{2}{*}{ UK } & Coef. & 0.678 & 0.001 & 0.060 & -0.671 & 0.001 & -0.004 \\
\hline & EIV & 1.261 & 0.436 & 0.165 & -0.927 & 0.660 & -0.803 \\
\hline \multirow[t]{6}{*}{0.999} & W.O.EIV & 1.373 & 0.524 & 0.241 & -1.190 & 0.856 & -1.011 \\
\hline & & SP & OI & RWSC & RWBC & RWIP & \\
\hline & Coef. & 0.001 & -0.001 & 0.399 & -0.161 & -0.720 & \\
\hline & EIV & 0.086 & -0.060 & 0.691 & -0.340 & -1.573 & \\
\hline & W.O.EIV & 0.129 & -0.078 & 0.910 & -0.435 & -2.005 & \\
\hline & & Const. & $\mathrm{AI}$ & $\mathrm{TP}$ & $\mathrm{JP}$ & WP & IP \\
\hline \multirow[t]{2}{*}{ JA } & Coef. & 0.358 & 0.000 & -0.114 & -0.390 & 0.002 & 0.004 \\
\hline & EIV & 1.402 & 0.026 & -0.380 & -0.582 & 1.512 & 1.370 \\
\hline \multirow[t]{6}{*}{0.851} & W.O.EIV & 1.630 & 0.034 & -0.541 & -0.833 & 2.071 & 1.901 \\
\hline & & SP & OI & RWSC & RWBC & RWIP & \\
\hline & Coef. & 0.006 & 0.020 & -0.030 & 0.253 & 0.612 & \\
\hline & EIV & 1.580 & 1.584 & -0.043 & 0.548 & 1.412 & \\
\hline & W.O.EIV & 2.619 & 2.541 & -0.061 & 0.790 & 2.167 & \\
\hline & & Const. & $\mathrm{AI}$ & $\mathrm{TP}$ & $\mathrm{JP}$ & WP & IP \\
\hline \multirow[t]{2}{*}{ CRR } & Coef. & 0.003 & 0.001 & 0.527 & -0.304 & -0.002 & -0.008 \\
\hline & EIV & 0.214 & 0.479 & 1.040 & -0.244 & -0.486 & -1.526 \\
\hline \multirow[t]{5}{*}{0.990} & W.O.EIV & 0.324 & 0.738 & 1.700 & -0.377 & -0.757 & -2.350 \\
\hline & & $\mathrm{SP}$ & OI & RWSC & RWBC & RWIP & \\
\hline & Coef. & 0.008 & 0.024 & -0.453 & -0.218 & -0.091 & \\
\hline & EIV & 0.776 & 0.620 & -0.668 & -0.395 & -1.123 & \\
\hline & W.O.EIV & 1.237 & 0.959 & -1.038 & -0.625 & -1.751 & \\
\hline
\end{tabular}

Note: 1. Const., Coef., EIV, and W.O.EIV mean respectively constant, coefficient, t-statistics with errors-in-variables adjustment, and t-statistics without errorsin-variables adjustment.

2. CRR in the bottom panel shows the results of U.S. stock portfolios that are used by CRR.

3. Numbers below country names are p-levels of the F-statistics corresponding to the linearity tests. 
The Japanese case is even more interesting. While none of the variables are significant with the EIV adjustment, five variables become significant without the EIV adjustment. These economic variables are unanticipated inflation, domestic industrial production growth, domestic stock index return, oil price, and rest-ofthe-world industrial production growth. Recall that CRR provided no support for the interpretation of oil price changes as a significant economic factor for pricing stocks. We find that oil price changes play a significant role in the Japanese case. This result is reassuring, because it seems difficult to dismiss oil price changes as a significant international economic factor. In sum, incorporation of international economic factors in pricing analysis appears to generate a better fit and a more appealing interpretation than the purely domestic economic factor case.

\section{International Economic State Variables and Asset Pricing}

A major drawback with the previous analysis is that it forces the imposition of undue priors on (a) dimensionality of the available economic variables (e.g., CRR picked five variables) and (b) linear structure between stock returns and the raw economic data (e.g., there is no a priori rationale that industrial production is a distinct economic state variable). The factor analytic approach, the results of which we now review, does not.

\section{Factor Estimation}

Table 5 reports the results of interbattery factor analysis on a combined set of macroeconomic variable innovations and stock returns for each pair of countries. Each test sample consists of stock returns for the U.S. and one other country, and macroeconomic variable innovations. These macroeconomic variables are listed in Table 1, and their associated ARIMA lag structure is listed in Table 2. All macroeconomic variables for the U.S. and the paired countries are included in the sample. The impact of the economic variables for the remaining five countries outside the pair are incorporated in the composite rest-of-the-world factors as depicted in Table 3.

In order to make a more meaningful interpretation of the estimated factors, the initial factors were rotated through the Varimax rotation. The empirical results of the rotation are reported in Table 6 . This interpretation focuses only on the priced factors, and this is accomplished by examining the collective feature of economic variables that load up relatively heavily on the significant factors.

\section{Factor Pricing}

Our approach uses factor scores as surrogates for the macroeconomic factors or international economic state variables that we investigate. (Factor score construction is described in Cho [6]). This approach contrasts with the traditional method which tests the pricing relationship on the initial factor loadings without knowledge of the relevant factors. The procedure allows us to test for pricing of 
Table 5

NUMBER OF INTERBATTERY COMMON FACTORS

\begin{tabular}{lcccc} 
Sample & \multicolumn{2}{c}{ Number of Variables } & \multicolumn{2}{c}{ Factors } \\
& Stocks & Macro. & Number & p-level \\
\hline US/CA & $60 / 28$ & 37 & & \\
US/UK & $60 / 48$ & 39 & 20 & 1.000 \\
US/FR & $60 / 24$ & 37 & 18 & 0.995 \\
US/GE & $60 / 22$ & 36 & 8 & 0.343 \\
US/AU & $60 / 26$ & 34 & 6 & 0.357 \\
US/JA & $60 / 55$ & 37 & 23 & 0.204 \\
& & & & 0.995 \\
US/UKA & $60 / 24$ & 39 & 7 & \\
US/UKB & $60 / 24$ & 39 & 7 & 0.222 \\
US/JAA & $60 / 27$ & 37 & 9 & 0.531 \\
US/JAB & $60 / 28$ & 37 & 9 & 0.190 \\
\hline
\end{tabular}

Note: Macro. means macroeconomic variables.

the individual factors. The test procedure utilizes a variant of the cross-sectional regression t-test [CSRT) developed by Shanken $[15,16]$, and discussed in the international context by Bodurtha [3].

The regression results for the pricing relationship between the prespecified factors and international stock returns are reported in Table 7 for ten pairs of countries. Note that the UK and JA stocks have been additionally divided into two separate groups each, UKA, UKB, JAA, and JAB, in order to have comparable number of stocks with the other country samples. For each pair, the five factor price estimates are reported with the highest estimated t-values (including constant terms) while making sure that no statistically significant factor is left out.

Consider the U.S./CA pair. Of the 20 factors reported in Table 5 for that pair, factors $3,6,14$, and 20 turn out to be the most significant. The $t$-values for the coefficients suggest that all four of these factors are priced for the U.S./CA pair. Following Shanken [15], we also test for linearity, an important asset pricing property. The U.S./CA pair passes the linearity test. On an overall basis, a linear pricing relationship is not rejected for any of the pairs reported in Table 7 , although for some pairs the factors are not significantly priced. Indeed, the factor price estimates for the U.S./JA pair are all insigificant.

The next task was to test for equality of risk premia (factor prices) across countries. For instance, for the U.S./CA pair a cross-sectional regression of the U.S. and Canada average stock returns were run separately against the 20 factor scores and also jointly to test for the equality of the coefficients between two countries. The p-level corresponding to the F-statistic is 0.361 , and consequently the null hypothesis of equal risk premia cannot be rejected, e.g., 05 level. 
Table 6

LIST OF VARIABLES WITH HIGH LOADINGS

ON THE ROTATED FACTORS

\begin{tabular}{|c|c|c|c|}
\hline No. & $\begin{array}{l}\text { Factor } \\
\text { Stock }\end{array}$ & $\begin{array}{l}\text { Cont. } \\
\text { Macro }\end{array}$ & High Loading Variables \\
\hline & & & U.S./CA \\
\hline 1 & 1.968 & 0.843 & USIP,CAIP, (CASP) \\
\hline 2 & 5.161 & 3.222 & $\begin{array}{l}\text { CATT,CATP,CAPP,CAWP,CAIR,CASP,USTP,CAIP } \\
\text { (USJP,CAM1,RWTP1) }\end{array}$ \\
\hline 3 & 3.070 & 4.407 & $\begin{array}{l}\text { USIR,RWTT1,RWPP1,RWWP1,RWM1,RWTP2,RWIP, } \\
\text { RWSP, CATP,RWTP1,USSP,RWEX, (USTP,USIM,WDGO) }\end{array}$ \\
\hline 4 & 0.816 & 1.319 & CAIM CAEX \\
\hline 5 & 0.906 & 0.662 & USJP, (CAIP,USIM) \\
\hline 6 & 3.375 & 1.066 & USTB, USM1,CAAI,CASP \\
\hline 7 & 1.402 & 0.769 & WDGO \\
\hline 8 & 1.168 & 2.346 & RWWP2,RWTT2,RWPP2,RWTP1,RWTP2, (RWIM) \\
\hline 9 & 1.089 & 0.703 & WDOI \\
\hline 10 & 1.334 & 0.750 & RWIM,RWEX \\
\hline 11 & 1.584 & 0.937 & USAI, (USWP) \\
\hline 12 & 1.250 & 0.879 & CAM1,CAAI \\
\hline 13 & 0.601 & 0.277 & CAIR \\
\hline 14 & 2.520 & 1.287 & USWP,USTP,USM1 \\
\hline 15 & 0.710 & 0.667 & RWIR \\
\hline 16 & 1.704 & 0.635 & USEX,USIM， (USTP) \\
\hline 17 & 0.907 & 0.541 & RWAI \\
\hline 18 & 1.974 & 0.307 & CASP, (USIM) \\
\hline 19 & 0.521 & 0.122 & ((USIR)) \\
\hline 20 & 6.109 & 0.982 & ÜSSP,CASP,RWSP \\
\hline
\end{tabular}

\begin{tabular}{rrrl}
\hline & & \multicolumn{1}{c}{ U.S./UK } \\
\hline 1 & 0.622 & 3.499 & $\begin{array}{l}\text { RWWP2,RWTT2,RWPP2,RWTP1,RWIM,RWIP,RWEX, } \\
\text { RWM11,RWSP2, (UKIP,RWM12) }\end{array}$ \\
2 & 0.711 & 0.575 & USIP \\
3 & 0.631 & 0.154 & ((RWIP) \\
4 & 0.995 & 1.660 & UKIM,UKEX,RWEX,RWIM \\
5 & 0.631 & 0.869 & USTB,WDGO,USIR \\
6 & 1.443 & 2.679 & RWTT1,RWWP1,RWPP1,RWM12,RWTP2,RWSP1,USTP \\
7 & 2.008 & 0.768 & USWP,USEX, (WDGO) \\
8 & 0.617 & 0.498 & UKAI \\
9 & 0.748 & 0.717 & USAI,USTP, (RWIP) \\
10 & 0.780 & 0.678 & RWAI \\
11 & 0.991 & 0.801 & USIM, (USTP) \\
12 & 1.009 & 1.062 & USJP,USM1,WDGO \\
13 & 12.701 & 1.235 & RWSP1,USSP, (RWM12,USTB,UKSP) \\
14 & 9.172 & 2.761 & UKPP,UKWP,UKTT,UKTP,UKSP,UKM1,UKIP,USTP, \\
& & & (UKIR) \\
15 & 1.308 & 0.783 & WDOI \\
16 & 1.213 & 0.723 & RWIR,UKIR,USTP \\
17 & 0.660 & 0.437 & UKIP,UKM1, (UKIR) \\
18 & 5.845 & 0.565 & UKSP, (UKTP)
\end{tabular}


Table 6 continued

Factor Cont.

No. Stock Macro High Loading Variables

U.S./UKA

\begin{tabular}{|c|c|c|c|}
\hline 1 & 0.798 & 1.896 & $\begin{array}{l}\text { RWPP2,RWWP2,RWTT2,RWEX,RWTP1,RWIM,RWIP, } \\
\text { (RWM11,WDOI,RWSP2) }\end{array}$ \\
\hline 2 & 0.766 & 0.606 & (USIP,USTB) \\
\hline 3 & 2.854 & 0.981 & USM1,USJP,RWSP1,WDGO (USSP) \\
\hline 4 & 8.302 & 2.304 & $\begin{array}{l}\text { UKSP,UKTP,UKIP,UKPP,UKIR,UKTT,UKWP,USSP, } \\
\text { RWSP1,RWTP2 }\end{array}$ \\
\hline 5 & 1.195 & 1.698 & $\begin{array}{l}\text { RWTP2,RWTT1,RWPP1,RWWP1,USTP, } \\
\text { (RWM11,WDOI,RWM12) }\end{array}$ \\
\hline 6 & 0.999 & 0.653 & UKIR,USIM,UKAI \\
\hline 7 & 1.439 & 0.758 & WDOI,USTB,RWIR, (USEX) \\
\hline
\end{tabular}

\begin{tabular}{|c|c|c|c|}
\hline \multicolumn{4}{|r|}{ U.S./UKB } \\
\hline 1 & 0.703 & 0.756 & WDOI,KWIR, USAI \\
\hline 2 & 6.449 & 2.222 & $\begin{array}{l}\text { RWSP1,RWTT1,RWWP1,USTB,RWPP1,USSP, } \\
\text { RWM12,RWTP2, (WDGO,USM1) }\end{array}$ \\
\hline 3 & 0.812 & 0.794 & UKAI, (USJP,UKIK, UKIM) \\
\hline 4 & 2.075 & 2.079 & $\begin{array}{l}\text { RWSP2,RWTP1,RWWP2,RWPP2,RWTT2,RWEX, } \\
\text { RWIP,RWM11,UKSP, (UKM1,UKPP,RWIM,UKWP,WDGO) }\end{array}$ \\
\hline 5 & 2.029 & 0.702 & UKIP, RWAI, (USEX) \\
\hline 6 & 6.267 & 2.165 & UKSP,UKPP,UKWP,UKTP,UKM1,UKTT,UKIP, (USTP) \\
\hline 7 & 5.269 & 0.854 & WDGO,RWSP1,USWP, (UKSP) \\
\hline \multicolumn{4}{|r|}{ U.S./FR } \\
\hline 1 & 0.793 & 0.613 & USTB \\
\hline 2 & 2.674 & 0.935 & USM1,USSP,RWSP1 \\
\hline 3 & 1.194 & 0.596 & WDOI \\
\hline 4 & 1.173 & 1.973 & $\begin{array}{l}\text { RWTT1,RWWP1,RWPP1,RWM1,RWTP,USIR,WDGO,RWIR, } \\
\text { (RWSP1) }\end{array}$ \\
\hline 5 & 10.713 & 3.489 & $\begin{array}{l}\text { FRSP,FRTP,FRIP,FRTT,FRPP,FRWP,RWSP1,RWPP2, } \\
\text { RWTT2,FREX,RWWP2,FRM1,RWTP,RWM1,FRIM, } \\
\text { (RWIP,USIR,USSP) }\end{array}$ \\
\hline 6 & 1.200 & 0.523 & USTP (RWTP) \\
\hline 7 & 0.738 & 0.519 & USEX \\
\hline 8 & 1.016 & 0.740 & RWSP2,RWAI,WDGO \\
\hline
\end{tabular}


Table 6 continued

Factor Cont.

No. Stock Macro High Loading Variables

\begin{tabular}{llll}
\hline & & \multicolumn{1}{c}{ U.S./GE } \\
\hline 1 & 9.056 & 6.107 & $\begin{array}{l}\text { GESP,GEWP,GEPP,GETT,GETP,GEIP,RWWP2, } \\
\text { RWTT2,GEM1,RWM11,RWPP,RWTP,RWSP,RWIP, } \\
\text { USIR,GEIR, (USSP,GEEX) }\end{array}$ \\
2 & 1.676 & 0.834 & WDGO,USEX, (RWIM) \\
3 & 1.751 & 0.810 & WDOI,GEAI, (RWAI,USIP,USIM) \\
4 & 0.844 & 0.750 & USAI,USIR, (RWSP,RWIR) \\
5 & 2.152 & 0.888 & USTP,USI,USM1 \\
6 & 3.047 & 1.669 & RWM12,RWTT1,RWWP1,RWSP,USTB,USSP \\
7 & 2.299 & 1.701 & GEIM,RWIM,GEEX,RWEX,USIM, (RWIP,WDOI,GEM1) \\
8 & 1.202 & 0.439 & RWAI \\
\hline
\end{tabular}

\begin{tabular}{llll}
\hline & & \multicolumn{1}{c}{ U.S./AU } \\
\hline 1 & 0.842 & 0.614 & AUAI,WDGO \\
2 & 1.282 & 1.630 & RWTT,USTP,RWWP,RWPP,RWTP1,RWM1,USJP \\
3 & 0.817 & 0.748 & AUIR,USM1,WDOI \\
4 & 4.451 & 2.915 & AUTT,AUWP,AUTP,AUM1,AUSP,AUPP,AUIP \\
5 & 2.672 & 0.964 & USSP,USWP, (USIM,USAI,AUAI) \\
6 & 1.041 & 0.928 & RWIM,WDOI,RWIR,RWEX \\
\hline
\end{tabular}

\begin{tabular}{cccl}
\hline & & \multicolumn{1}{c}{ U.S./JA } \\
\hline 1 & 10.296 & 5.017 & $\begin{array}{l}\text { JATT,JATP,JAPP,JASP,JAM1,JAIP,JAWP,USIR,JAIR,JAEX, } \\
\text { (RWP1) }\end{array}$ \\
2 & 0.793 & 0.569 & USM1 \\
3 & 1.029 & 1.399 & RWIM,RWEX, (JAIP) \\
4 & 0.638 & 0.567 & RWIR \\
5 & 1.320 & 0.749 & USWP \\
6 & 1.447 & 0.906 & WDOI \\
7 & 0.443 & 0.627 & USEX \\
8 & 0.953 & 0.803 & USIP \\
9 & 2.305 & 3.982 & RWWP1,RWPP1,RWM1,RWTT1,RWTP2,RWIP,JAIR,RWSP, \\
& & & RWIR, (USIR) \\
10 & 1.355 & 0.709 & USJP \\
11 & 1.184 & 0.654 & USAI, (JAAI) \\
12 & 1.120 & 0.585 & USTP \\
13 & 0.975 & 0.757 & RWAI \\
14 & 1.232 & 0.424 & WDGO \\
15 & 7.614 & 1.197 & USSP,RWSP \\
16 & 0.811 & 0.723 & JAIM \\
17 & 1.561 & 2.185 & RWPP2,RWWP2,RWTT2,JAEX,WDGO \\
18 & 1.142 & 0.574 & RWTP1 \\
19 & 1.681 & 0.533 & JAAI \\
20 & 1.425 & 0.712 & USIM \\
21 & 0.935 & 0.625 & USTB \\
22 & 0.950 & 0.336 & JAEX \\
23 & 0.545 & 0.232 & RWIP \\
& & &
\end{tabular}


Table 6 continued

\begin{tabular}{|c|c|c|c|}
\hline No. & $\begin{array}{l}\text { Factor } \\
\text { Stock }\end{array}$ & $\begin{array}{l}\text { Cont. } \\
\text { Macro }\end{array}$ & High Loading Variables \\
\hline & & & U.S./JAA \\
\hline 1 & 1.498 & 0.673 & RWIR, (JAEX) \\
\hline 2 & 1.068 & 0.564 & USIM,RWEX, (RWIM,USSP) \\
\hline 3 & 0.934 & 0.440 & USTP \\
\hline 4 & 2.890 & 2.543 & JATP,JASP, JATT,JAM1,JAIP,USIP,JAPP,JAIR,JAWP(USEX) \\
\hline 5 & 1.849 & 1.478 & $\begin{array}{l}\text { RWWP2,RWPP2,RWTT2,USM1,USJP,USSP,JAEX, } \\
\text { (RWSP,WDGO) }\end{array}$ \\
\hline 6 & 3.131 & 5.893 & $\begin{array}{l}\text { RWTT1,RWWP1,RWM1,RWPP1,RWTP2,RWIP,JATT,JAPP, } \\
\text { JAWP,RWIR,JATP,JASP,USIR,JAIP,JAM1,RWSP,JAIR, } \\
\text { WDGO,JAEX, (RWIM) }\end{array}$ \\
\hline 7 & 1.503 & 0.913 & WDOI \\
\hline 8 & 7.765 & 1.274 & USSP,RWSP,USWP,USTB,RWTP1, (RWPP2) \\
\hline 9 & 0.805 & 0.959 & RWAI,JAIP,JAIM，USTB，(JASP) \\
\hline
\end{tabular}

\begin{tabular}{|c|c|c|c|}
\hline \multicolumn{4}{|r|}{ U.S./JAB } \\
\hline 1 & 1.048 & 0.465 & USTP, (JAIR) \\
\hline 2 & 0.817 & 0.789 & RWIR,USJP, (USTP,WDOI,RWEX) \\
\hline 3 & 1.315 & 0.787 & JAAI, (USAI,WDOI) \\
\hline 4 & 5.411 & 6.327 & $\begin{array}{l}\text { JATP,JAIP,JATT,JAPP,JASP,JAWP,RWTT1,RWPP1, } \\
\text { JAM1,RWWP1,RWM1,RWTP2,RWIP,USIR,JAIR,RWSP, } \\
\text { WDGO, (RWIR,RWTP1) }\end{array}$ \\
\hline 5 & 5.890 & 1.960 & $\begin{array}{l}\text { USSP, RWSP,RWPP2,RWWP2,RWTT2,WDGO, } \\
\text { (RWTP1,USTB,JAEX) }\end{array}$ \\
\hline 6 & 1.030 & 0.838 & RWAI, (JASP,JÁTP) \\
\hline 7 & 3.195 & 0.739 & USWP,WDGO, (USSP) \\
\hline 8 & 1.791 & 0.804 & WDOI,USTB, (USEX) \\
\hline 9 & 1.141 & 0.903 & USM1,USIM, (JAIM,USIP) \\
\hline
\end{tabular}

By the same token, equality of risk premia cannot be rejected for the remaining pairs, except for the pairs involving Japan and the U.S. As discussed in Cho, Eun and Senbet [7] and Bodurtha [3], inequality of risk premia could be attributable to either (a) capital market segmentation between countries or (b) invalidity of the asset pricing model itself. The evidence for the U.S. and Canada fails to support market segmentation but does support a significant pricing relationship, since not only are the risk premium estimates insignificantly different across the two countries, but the factor price estimates are significant. The evidence for the U.S. and Germany is almost equally encouraging. The U.S. and France case, while weaker, is also supportive of the absence of capital market segmentation and a significant pricing relationship involving two common factors. The case of the U.S. and Australia resembles the pair involving the U.S. and Japan in that equality of risk premia is very weakly supported and only one factor shows up as a significant pricing determinant. Nevertheless, except for one Japanese stock sample, the integration hypothesis is maintained. 
Table 7

PRICING RESULTS OF FACTOR ANALYTIC STUDY

\begin{tabular}{|c|c|c|c|c|c|c|}
\hline \multicolumn{2}{|l|}{ Sample } & \multicolumn{5}{|c|}{ Five Selected Factors with High t-statistics } \\
\hline $\begin{array}{r}\text { US/CA } \\
1.000 \\
0.361\end{array}$ & $\begin{array}{l}\text { Factors } \\
\text { Coef. } \\
\text { t-stat. }\end{array}$ & $\begin{array}{l}\text { Const. } \\
0.001 \\
1.707\end{array}$ & $\begin{array}{c}3 \\
-0.237 \\
-2.452\end{array}$ & $\begin{array}{c}6 \\
-0.194 \\
-2.022\end{array}$ & $\begin{array}{c}14 \\
-0.198 \\
-2.050\end{array}$ & $\begin{array}{c}20 \\
-0.246 \\
-2.541\end{array}$ \\
\hline US/UK & $\begin{array}{l}\text { Factors } \\
\text { Coef. } \\
\text { t-stat. }\end{array}$ & $\begin{array}{l}\text { Const. } \\
1.194 \\
7.884 \\
\end{array}$ & $\begin{array}{c}3 \\
0.074 \\
0.847 \\
\end{array}$ & $\begin{array}{c}9 \\
0.082 \\
0.935 \\
\end{array}$ & $\begin{array}{c}10 \\
-0.154 \\
-1.757 \\
\end{array}$ & $\begin{array}{c}18 \\
0.097 \\
1.103 \\
\end{array}$ \\
\hline $\begin{array}{c}\text { US/UKA } \\
0.990 \\
0.613 \\
\end{array}$ & $\begin{array}{l}\text { Factors } \\
\text { Coef. } \\
\text { t-stat. }\end{array}$ & $\begin{array}{l}\text { Const. } \\
0.893 \\
4.419 \\
\end{array}$ & $\begin{array}{c}3 \\
0.127 \\
1.418 \\
\end{array}$ & $\begin{array}{c}5 \\
-0.076 \\
-0.850 \\
\end{array}$ & $\begin{array}{c}6 \\
-0.078 \\
-0.881 \\
\end{array}$ & $\begin{array}{c}7 \\
-0.057 \\
-0.631 \\
\end{array}$ \\
\hline $\begin{array}{c}\text { US/UKB } \\
0.972 \\
0.472 \\
\end{array}$ & $\begin{array}{l}\text { Factors } \\
\text { Coef. } \\
\text { t-stat. }\end{array}$ & $\begin{array}{l}\text { Const. } \\
1.074 \\
5.247 \\
\end{array}$ & $\begin{array}{c}1 \\
0.094 \\
1.077 \\
\end{array}$ & $\begin{array}{c}2 \\
0.043 \\
0.472 \\
\end{array}$ & $\begin{array}{c}5 \\
0.053 \\
0.602 \\
\end{array}$ & $\begin{array}{c}6 \\
-0.038 \\
-0.425 \\
\end{array}$ \\
\hline $\begin{array}{r}\text { US/FR } \\
0.996 \\
0.117 \\
\end{array}$ & $\begin{array}{l}\text { Factors } \\
\text { Coef. } \\
\text { t-stat. }\end{array}$ & $\begin{array}{l}\text { Const. } \\
0.013 \\
3.647 \\
\end{array}$ & $\begin{array}{c}2 \\
-0.152 \\
-1.737 \\
\end{array}$ & $\begin{array}{c}4 \\
-0.046 \\
-0.516 \\
\end{array}$ & $\begin{array}{c}7 \\
-0.125 \\
-1.425 \\
\end{array}$ & $\begin{array}{c}8 \\
-0.180 \\
-1.982 \\
\end{array}$ \\
\hline $\begin{array}{r}\text { US/GE } \\
0.939 \\
0.134\end{array}$ & $\begin{array}{l}\text { Factors } \\
\text { Coef. } \\
\text { t-stat. }\end{array}$ & $\begin{array}{l}\text { Const. } \\
0.024 \\
7.577\end{array}$ & $\begin{array}{c}1 \\
0.162 \\
1.162\end{array}$ & $\begin{array}{c}5 \\
0.255 \\
2.773 \\
\end{array}$ & $\begin{array}{c}6 \\
-0.165 \\
-1.886 \\
\end{array}$ & $\begin{array}{c}7 \\
-0.133 \\
-1.500 \\
\end{array}$ \\
\hline $\begin{array}{r}\text { US/AU } \\
0.963 \\
0.097 \\
\end{array}$ & $\begin{array}{l}\text { Factors } \\
\text { Coef. } \\
\text { t-stat. }\end{array}$ & $\begin{array}{l}\text { Const. } \\
0.007 \\
2.517 \\
\end{array}$ & $\begin{array}{c}1 \\
-0.078 \\
-0.888 \\
\end{array}$ & $\begin{array}{c}2 \\
-0.083 \\
-0.936 \\
\end{array}$ & $\begin{array}{c}4 \\
-0.027 \\
-0.286 \\
\end{array}$ & $\begin{array}{c}5 \\
-0.202 \\
-2.310 \\
\end{array}$ \\
\hline US/JA & $\begin{array}{l}\text { Factors } \\
\text { Coef. } \\
\text { t-stat. }\end{array}$ & $\begin{array}{l}\text { Const. } \\
0.804 \\
4.393 \\
\end{array}$ & $\begin{array}{c}1 \\
-0.119 \\
-1.229 \\
\end{array}$ & $\begin{array}{c}3 \\
0.118 \\
1.303 \\
\end{array}$ & $\begin{array}{c}6 \\
-0.125 \\
-1.371 \\
\end{array}$ & $\begin{array}{c}8 \\
-0.138 \\
-1.585 \\
\end{array}$ \\
\hline $\begin{array}{c}\text { US/JAA } \\
0.494 \\
0.022 \\
\end{array}$ & $\begin{array}{l}\text { Factors } \\
\text { Coef. } \\
\text { t-stat. }\end{array}$ & $\begin{array}{l}\text { Const. } \\
0.534 \\
4.410 \\
\end{array}$ & $\begin{array}{c}1 \\
0.075 \\
0.848 \\
\end{array}$ & $\begin{array}{c}2 \\
-0.063 \\
-0.718 \\
\end{array}$ & $\begin{array}{c}3 \\
-0.086 \\
-0.969 \\
\end{array}$ & $\begin{array}{c}8 \\
0.086 \\
0.965 \\
\end{array}$ \\
\hline $\begin{array}{r}\text { US/JAB } \\
0.635 \\
0.084\end{array}$ & $\begin{array}{l}\text { Factors } \\
\text { Coef. } \\
\text { t-stat. }\end{array}$ & $\begin{array}{l}\text { Const. } \\
1.033 \\
7.992\end{array}$ & $\begin{array}{c}1 \\
0.066 \\
0.743\end{array}$ & $\begin{array}{c}3 \\
-0.066 \\
-0.745\end{array}$ & $\begin{array}{c}4 \\
0.150 \\
1.526\end{array}$ & $\begin{array}{c}9 \\
0.090 \\
1.022\end{array}$ \\
\hline
\end{tabular}

Note: 1. The first and second number under the sample name represent p-levels of F-statistics corresponding to the linearity tests and equal risk premia tests, respectively.

2. The $\mathbf{t}$-statistics are adjusted for errors-in-variables.

3. Const. and Coef. mean constant and coefficent, respectively.

At this stage, it may be of some interest to provide a more meaningful interpretation of the significant factor price estimates. Looking at the U.S./CA pair again in Tables 6 and 7 , it is noticeable that factor 3 loads heavily on a combination of the rest-of-the-world aggregates, including the stock market. Factor 6 loads on the U.S. Treasury bill rate and money supply, and Canadian anticipated inflation and stock prices. The presence of the stock price index in this factor leads us to view it as mixed and hard to interpret. Factor 14 is rather interesting, and can be viewed as depicting monetary conditions in the U.S. The collective feature of 
macroeconomic variables in factor 20 is characterized by the stock market conditions, involving country and the rest-of-the-world stock return indices, and hence this factor is distinctive economically. The factors involving France and Australia seem dominated by stock market conditions as reflected in factors 2 and 8 for the U.S./FR case and in factor 5 for the U.S./AU case. The factor interpretation for the German case is unclear, although again the rest-of-the-world and U.S. stock markets play a significant role as reflected in factors 1 and 6 of the U.S./GE. The pricing of those factor scores that involve stock market indices may be viewed as contradictory to the CRR results that indicated an insignificant role for the U.S. stock index. However, our approach adopts an international perspective, and the rest-of-the-world stock return index seems to play a significant role.

\section{CONCLUSION}

This paper has examined the role of international economic state variables in asset pricing by taking the view that stock returns respond to international factors. The empirical analogs of these factors are determined by an a priori specification of measured economic determinants and through the interbattery factor analysis. In our tests based on prior factors, we are not able to replicate the result of ChenRoll-Ross [5] on the domestic component of our data due primarily to our shorter sample period. However, we do find evidence that several of the international analogs of the CRR domestic variables, stock index returns, industrial production, bond returns, unanticipated inflation and oil prices are significant in explaining the cross-section of average stock returns in our sample. This finding provides support for an international dimension in asset pricing, even in the CRR context. Given that investors attempt to diversify their portfolios internationally, this result is reassuring. Thus, our results provide strong support for an international view of economic forces that impact the stock market. International economic forces in our pricing analysis allow us to generate a better fit and a more appealing interpretation than the purely domestic case.

Our expanded analysis, which utilizes the factor-analytic technique and a broader set of macroeconomic variables, generates results which are supportive of a linear pricing relationship for international stock returns and equality of risk premia across countries, except for the U.S.-Japan pair. However, the latter paired case and the U.S./UK pair exhibit largely insignificant pricing factors. Thus, there is very little evidence consistent with mild or severe segmentation across financial markets for the advanced economies in our sample as they relate to the U.S. stock market. The macroeconomic variables that load heavily on the significant factors vary across country pairs. Both domestic and international variables load on these factors. However, the primary variables across these factors are stock index returns.

Some concerns and areas of future research are evident in the analysis of our results. First, our tests may not be sufficiently powerful. Therefore, our failure to reject the market integration hypothesis must not be taken as strong evidence against some degree of market segmentation. The power of our tests could be 
improved in two ways. First, different equity return samples may lead to an improvement. In the U.S. domestic case, forming asset portfolios based on sizerankings improves the power of the testing procedures that we use. Potentially, the market value ranking of firms or some other means of sample stratification will also be useful in the international context. Second, we could impose the crosssectional constraints implied by the fact that our factors are traded portfolios. This alternative, applied by Shanken and Weinstein [17] and Bodurtha [3], was discussed and analyzed for two factor models by Mackinlay [13]. Nevertheless, the application of these factor pricing constraints is somewhat complicated in the calculation of the factor expected return estimates.

Finally, recent evidence on the importance of time-varying risk premia indicates concern with our assumption of a constant covariance structure for the joint space of asset returns and economic variables. This time variation may be quite important in the context of our international tests due to substantial structural changes in international markets during our sample period.

\section{REFERENCES}

1. Anderson, T. and H. Rubin, "Statistical Inference in Factor Analysis," Proceedings of the Third Berkeley Symposium on Mathematical Statistics and Probabilities, Volume 5, 1956, pp. 111-150.

2. Bartlett, M., "The Statistical Conception of Mental Factors," British Journal of Psychology, Volume 28, 1937, pp. 97-104.

3. Bodurtha, J., "The International Factors and U.S. Equity Excess Returns," Working paper, University of Michigan, 1988.

4. Browne, M., "The Maximum-Likelihood Solution in Inter-Battery Factor Analysis," British Journal of Mathematical and Statistical Psychology, Volume 32, 1979, pp. 75-86.

5. Chen, N., R. Roll and S. Ross, "Economic Forces and the Stock Market," Journal of Business, Volume 59, 1986, pp. 383-403.

6. Cho, D., "On Testing the Arbitrage Pricing Theory: Inter-Battery Factor Analysis," Journal of Finance, Volume 39, 1984, pp. 1485-1502.

7. Cho, D., C. Eun and L. Senbet, "International Arbitrage Pricing Theory: An Empirical Investigation," Journal of Finance, Volume 41, 1986, pp. 313-329.

8. Cho, D. and S. Pak, "Multifactor Pricing Model with Macroeconomic Variables," Working Paper, University of Wisconsin, 1986.

9. Fama, E. and J. MacBeth, "Risk, Return, and Equilibrium: Empirical Tests," Journal of Political Economy, Volume 38, 1973, pp. 607-636.

10. Harman, H., Modern Factor Analysis, University of Chicago Press, Chicago, 1967.

11. Ibbotson, R., R. Carr and A. Robinson, "International Equity and Bond Returns," Financial Analysts Journal, July/August 1982, pp. 61-83.

12. Kim, J. and C. Mueller, Factor Analysis, A Sage University Paper, 1978.

13. Mackinlay, C., "On Multivariate Tests of the CAPM," Journal of Financial Economics, Volume 18, 1987, pp. 341-371. 
14. Roll, R. and S. Ross, "An Empirical Investigation of the Arbitrage Pricing Theory," Journal of Finance, Volume 33, 1980, pp. 1073-1103.

15. Shanken, J., "Multivariate Tests of the Zero-Beta CAPM," Journal of Financial Economics, Volume 14, 1985, pp. 327-348.

16. Shanken, J., "On the Estimation of Beta-Pricing Models," Working Paper, Rochester, 1988.

17. Shanken, J. and M. Weinstein, "Testing Multifactor Pricing Relations with Prespecified Factors, " Working Paper, University of Southern California, 1986.

18. Steiger, J., "Factor Indeterminancy in the 1930's and 1970's: Some Interesting Parallels," Psychometrika, Volume 44, 1979, pp. 157-167.

19. Thurstone, L., The Vectors of Mind, University of Chicago Press, Chicago, 1935.

\section{FOOTNOTES}

1. CRR recognize that this relationship is not necessarily a one-way street, particularly in the long run. All economic variables can be viewed as endogenous in the ultimate sense. Even for the short-run case, the use of a junk bond premium may not be accomplishing the intended goal of capturing shifts in risk premia. This variable was used on the grounds that the bond market (i.e., a non-equity market) is treated as exogenous to the stock market.

2. The market value weights for the RWSC and RWBC are as follows:

\begin{tabular}{cccccccc} 
& US & CA & UK & FR & GE & AU & JA \\
\hline RWSC & 56.88 & 5.78 & 9.69 & 2.73 & 3.64 & 3.05 & 18.23 \\
RWBC & 45.27 & 3.84 & 9.21 & 4.68 & 12.28 & 0.77 & 23.95
\end{tabular}

3. We might add that our adjustment of errors-in-variables (EIV) based on Shanken's procedure is different from CRR's portfolio grouping approach. Consequently, our results without EIV adjustment are more readily comparable to CRR's results. 